\title{
CONTRIBUIÇÕES DE UMA OFICINA NA FORMAÇÃO DE PROFESSORES: DISCUSSÃO SOBRE A IMPORTÂNCIA DO DESENHO GEOMÉTRICO NAS AULAS DE GEOMETRIA
}

\author{
Renan Oliveira Altoé, Gabriel Nazarh Aprahamian de Oliveira Romão, Thamires Belo de \\ Jesus
}

Instituto Federal de Educação, Ciência e Tecnologia do Espírito Santo

Vitória, Cachoeiro do Itapemirim e Vila Velha, Espírito Santo

E-mail: renan_altoe@hotmail.com,gabriel.hamian@gmail.com, thamiresbelo@yahoo.com.br

Resumo: Este trabalho tem como objetivo analisar que contribuições a Oficina "Desenho Geométrico: Construções Fundamentais", ministrada em Agosto de 2014 no VI Seminário da Licenciatura em Matemática (VI SEMAT) do IFES, câmpus Cachoeiro de Itapemirim - ES, produziu à respeito da importância do Desenho Geométrico nas aulas de Geometria e na Formação Inicial e/ou Continuada de Professores. O aporte teórico das discussões promovidas durante a Oficina descrevem-se neste trabalho. É um estudo qualitativo, tendo os dados coletados por meio de observações e questionário aberto. Os resultados indicaram contribuições desde aspectos didático-pedagógicos até a consciência da necessidade de aprofundamento teórico-prática sobre o Desenho Geométrico. Associou-se, também, aulas mais dinâmicas e atrativas..

Palavras-chave: desenho geométrico, ensino-aprendizagem, formação de professores, geometria, Educação Básica.

\section{OF A WORKSHOP CONTRIBUTIONS IN TEACHER EDUCATION: DISCUSSION ON GEOMETRIC DESIGN OF IMPORTANCE IN CLASSES GEOMETRY}

Abstract: This work aims to analyze what contributions the Workshop "Geometric Drawing: Key Constructions", delivered in August 2014 at the Sixth Seminar in Mathematics (VI SEMAT) of IFES, campus Itapemirim - ES, produced regarding the importance of Geometrical drawing in geometry classes and Initial Training and/or Continuing Teachers. The theoretical basis of the discussions held during the workshop are described in this work. It is a qualitative study, with data collected through observations and open questionnaire. The results indicated contributions from didactic and pedagogical aspects to the awareness of the need for theoretical and practical deepening of the Geometric Design. He joined also classes more dynamic and attractive.

Keywords: geometric design, teaching and learning, teacher training, geometry, basic education.

Recebido em 29/09/2015. Publicado em 30/09/2016. 


\section{INTRODUÇÃO}

Dentre os objetivos do Ensino de Geometria, é importante destacar o desenvolvimento do pensamento geométrico. Para além, Hoffer (1981) aponta às visuais, de aplicação ou de transferência, de desenho e construção, de comunicação e de lógica, como habilidades inerentes ao ensino e à aprendizagem de Geometria. Ao mencionar "desenho e construção", o autor sinaliza aprendizagens que supostamente versam para a utilização de determinadas ferramentas ${ }^{1}$, que podem potencializar a criatividade, coadjuvando na resolução de problemas geométricos.

As reflexões acima propõem-se associar, ao Ensino de Geometria, uma disciplina que experimentou um descaso no âmbito educacional brasileiro: o Desenho Geométrico. No entanto, Marmo e Marmo (1994) apontam que o Desenho Geométrico possibilita concretizar e significar os conhecimentos teóricos da Geometria, fortalecendo assim, o seu ensino e sua importância nas aulas de matemática. Sua inserção auxilia na construção de figuras geométricas, proporcionando momentos de reflexão-ação-reflexão. O Desenho Geométrico, além de contribui para o estudo de Geometria, possibilita desenvolver o raciocínio lógico e é muito útil na obtenção de soluções aproximadas de problemas matemáticos (BONGIOVANNI; SAVIETTO; MOREIRA, 2007).

Com base nessas contribuições, Lisboa (2013) relata que o Parecer 265/62, que determinava o currículo mínimo obrigatório para a Licenciatura em Matemática, apresentava o Desenho Geométrico como componente curricular obrigatório. Contudo, a partir da Lei 9394/96, não havia mais obrigatoriedade de um currículo mínimo para o Ensino Superior e as instituições tinham autonomia para reestruturar suas matrizes curriculares. Segundo o autor, o Parecer 1.302/2001, que descreve o núcleos comuns que deveriam ser trabalhados nas Licenciaturas em Matemática, não apresentava de forma explícita o Desenho Geométrico e, portanto, esse fato impulsionado para o descaso e enfraquecimento enquanto componente curricular autônomo. Assim, questionamo-nos: Como poderão, professores de matemática, incorporarem o Desenho Geométrico nas aulas de Geometria se por vezes desconhecem a sua importância e a utilidade de suas ferramentas?

\footnotetext{
1 No decorrer deste trabalho, a menção à palavra "ferramentas" alude a: régua, compasso, esquadros e transferidores, consideradas importantes nos estudos de Desenho Geométrico e na aprendizagem de Geometria.
} 
Altoé, Romão, Jesus, 2016 - Formação Inicial e Continuada

A partir desse questionamento, Altoé e Romão (2014) propuseram uma Oficina intitulada "Desenho Geométrico: Construções Fundamentais", ministrada no VI Seminário da Licenciatura em Matemática (VI SEMAT) do Ifes, câmpus Cachoeiro de Itapemirim, que teve como objetivo discutir o papel do Desenho Geométrico nas aulas de Geometria e sua relevância enquanto temática na Formação Inicial e/ou Continuada de Professores. Este objetivo desmembrou-se nos seguintes objetivos específicos: a) verificar a importância da disciplina de Desenho Geométrico na Formação Inicial e/ou Continuada de Professores; b) aferir a relevância do Desenho Geométrico nas aulas de Geometria e c) apurar que contribuições foram produzidas pela Oficina à formação docente dos participantes. O público alvo contou com licenciandos em matemática e professores de Ensino Fundamental e Médio da Educação Básica. As discussões durante a Oficina tomara como base os estudos de Kaleff (2005), Santos e Nacarato (2014), Fonseca et al. (2011), Lorenzato (1995), Eves (2004), Boyer (2010) e Mol (2013), que sustentaram acerca da importância da Geometria e Marinho et al (2010), Albrecht e Oliveira (2013), Queiroz (2010), Guarnieri (2011) e Zuin (2002; 2003) que discorreram em relação ao Desenho Geométrico. As atividades propostas, no decorrer da Oficina, foram elaboradas pelos autores.

Assim, o objetivo deste trabalho é analisar que contribuições a Oficina produziu a respeito da importância do Desenho Geométrico nas aulas de Geometria e na Formação Inicial e/ou Continuada de Professores, a partir das análises das respostas aos objetivos específicos apontados acima. Trata-se de um estudo de natureza qualitativa fundamentado em Fiorentini e Lorenzato (2007), tendo a coleta de dados realizada por meio de observações e questionário aberto, respondido voluntariamente.

\section{BREVES APONTAMENTOS HISTÓRICOS DA GEOMETRIA E SUA IMPORTÂNCIA NOS CURRICULOS ESCOLARES}

Não há como negar que o mundo é geométrico!

As origens da Geometria despontaram-se de diversas partes da Europa Ocidental. Segundo Eves (2004), a geometria babilônica está intimamente relacionada com a mensuração prática, mas sua marca principal é a de caráter algébrico. Em contrapartida, a civilização egípcia também contribuiu na descoberta da Geometria. Nesse sentido, Eves (2004) anuncia que dos 110 (cento e dez) 
problemas dos papiros de Moscou ${ }^{2}$ e Rhind ${ }^{3}, 26$ (vinte e seis) são de caráter geométrico. Vários deles decorrem de fórmulas de mensuração que foram necessárias para o cálculo de áreas de terras e volumes de grãos. Similarmente, os relatos de Boyer (2010) afirmam que Heródoto mantinha a ideia de que a Geometria se originou no Egito, diante da necessidade prática de fazer medidas de terras após as inundações anuais do Rio Nilo. Com base nisso, pode-se dizer que a Geometria teve sua origem provável no povo egípcio e "[...] a geometria teórica originou-se da mensuração" (EVES, 2004, p. 57).

Ao desenvolvimento da Geometria vincula-se a figura de Euclides de Alexandria, matemático da escola platônica e conhecido como Pai da Geometria. Estudioso da escola de Atenas, alcançou seu prestígio devido a maneira com a qual ensinava a Geometria e Álgebra por meio de compasso e régua, o que culminou na escrita de sua obra "Os Elementos", dando origem à Geometria Euclidiana (MOL, 2013). Para Santos e Nacarato (2014, p. 14) “o modelo euclidiano tornou-se uma referência tanto no campo da ciência como no do ensino" até perder forças com o Movimento da Matemática Moderna entre 1970 e 1980, sendo considerada irrelevante na formação intelectual do aluno. Esse Movimento buscou aproximar a matemática da Escola Básica com a matemática produzida pelas academias, enfatizando o ensino de álgebra, teoria dos conjuntos e demais conteúdos matemáticos de caráter científico. Apesar desse descaso, é unânime ${ }^{4}$ a importância do ensino de Geometria na formação intelectual e/ou cidadã.

É valoroso compreender que é através dos objetos presentes no cotidiano que se materializa a Geometria. Dessa forma, é de consenso geral que o estudo desse ramo da matemática possibilita organizar o pensamento que decorre do reconhecimento e da análise das propriedades características de modelos geométricos, estes que representam objetos do mundo (KALEFF, 2005). De forma similar, Lorenzato (1995, p. 6) aponta que "a Geometria pode esclarecer situações abstratas, facilitando a comunicação da ideia matemática" e que o ensino das formas geométricas deve ser precedidos da exploração do espaço físico real do educando (FONSECA et al, 2014). Apesar dos alunos já terem contato com a Geometria antes de adentrarem à escola, acredita-se

\footnotetext{
2 Papiro Moscou ou Golenischev é um texto matemático que contém 25 problemas, tendo cerca de 18 pés de comprimento por cerca de três polegadas de altura (EVES, 2004).

${ }^{3}$ Papiro Rhind (ou Ahmes), é um texto matemático na forma de manual prático que contém 85 problemas copiados em escrita hierática pelo escriba Ahmes de um trabalho mais antigo (EVES, 2004).

${ }^{4}$ Os próprios autores que fundamentam esta pesquisa são exemplos dessa unanimidade.
} 
que o desenvolvimento do pensamento geométrico se enfatiza nesse ambiente, onde a criança ampliar e sistematizar seu conhecimento de espaço em que vive (FONSECA et al, 2014).

Tomando-se por base o texto "Por que não ensinar geometria?", de Lorenzato (1995), é possível encontrar uma série de justificativas para se ensinar geometria nas escolas: a) sem estudar Geometria as pessoas não desenvolvem o pensar geométrico ou raciocínio visual, tendo dificuldades em resolver situações de vida que forem geometrizadas; b) sem conhecer Geometria a leitura interpretativa do mundo torna-se incompleta; c) aprender geometria ajuda resolver situações escolares que requerem percepção espacial; d) é um excelente meio para identificar o nível de compreensão e raciocínio da criança; e) a Geometria valoriza o descobrir, o conjecturar e o experimentar e f) a Geometria é um excelente apoio as outras disciplinas.

Em síntese, pode-se perceber a importância atribuída ao Ensino de Geometria nas escolas, sendo ela "[...] um campo fértil para se trabalhar com situações-problema e é um tema pelo qual os alunos costumam se interessar naturalmente" (BRASIL, 1997, p. 39). Lorenzato (1995, p. 6-7) afirma que "a Geometria é a mais eficiente conexão didático-pedagógica que a Matemática possui: ela se interliga com a Aritmética e com a Álgebra porque os objetos e relações dela correspondem aos das outras". Um detalhe relevante é destacado por Fonseca et al. (2014) ao salientar que o desenho é um recurso didático importante na aprendizagem de Geometria. Essa anunciação é o vetor diretor da próxima seção que aludirá a respeito do Desenho Geométrico.

\section{SUCINTA HISTÓRIA E PERCURSSO DO DESENHO GEOMETRICO NO BRASIL: QUAL É A SUA RELAÇÃO COM A GEOMETRIA?}

Desenhar não é algo novo!

As representações na Antiguidade relacionavam-se com as práticas existentes da época. Desenhava-se para comunicar-se, para ensinar e aprender e para representar fatos cotidianos. Assim, para Marinho et al. (2010, p. 1),

[...] desde o tempo pré-histórico, o homem utilizava os símbolos gráficos para se comunicar, com o objetivo de demonstrar de uma maneira física, as sensações que Ihes eram inerentes, de forma que estas sensações pudessem ficar documentadas. 
Do exposto acima infere-se o nascimento do Desenho como linguagem e representação gráfica. Em Geometria, por exemplo, desenhar é comunicar ideias e ações da escrita. Para Marinho et al (2010), a escrita nada mais é do que a combinação de símbolos.

Segundo Marinho et al. (2010) a necessidade de medir terrenos, necessidade essa, que deu origem ao conceito de Geometria, pelos povos egípcios e babilônicos, contribuiu para o nascimento do Desenho Geométrico. Muito se desenvolveu nessa área, mas segundo Zuin (2003, p. 512-513),

No final do século XIX, a importância do ensino do Desenho nas escolas brasileiras foi enfatizada por Rui Barbosa, ao propor mudanças através da "Reforma do Ensino Secundário e Superior", de 1882, e "Reforma do Ensino Primário e várias Instituições Complementares da Instrução Pública", elaborada em 1883.

A preocupação de Rui Barbosa voltava-se para o desenvolvimento educacional do país, seja na Educação Básica que no Ensino Superior. Suas propostas derivaram da influência de outros países, onde o Desenho e o Desenho Geométrico eram considerados importantes no desenvolvimento de habilidades e conhecimentos para atender a áreas específicas (QUEIROZ, 2010), quer seja da matemática que de áreas afins.

Segundo Marinho et al. (2010, p. 1),

O Desenho Geométrico permaneceu no Brasil como uma componente curricular escolar durante 40 anos - de 1931 a 1971. Apesar da Lei de Diretrizes e Bases da Educação Nacional [LDB] de 1961, propor opções onde o Desenho não seria uma matéria obrigatória nos currículos, ela permaneceu até aparecer neste mesmo período uma emergente desvalorização da disciplina.

Mesmo com as orientações da LDB de 1961, o Desenho Geométrico continuou sendo ensinado por algum período nas escolas de Educação Básica. Contudo, com a promulgação da LDB 5692/71, "muitas escolas deixaram de aplicar as construções geométricas como uma componente curricular obrigatória, passando esta a ser uma disciplina do núcleo optativo [...] (MARINHO et al, 2010, p. 2). Segundo Zuin (2002), muitos professores da área de Desenho Geométrico na década de 1980, 
tentaram, por meio de publicações e livros, o seu retorno como componente curricular, mas não houve êxito.

Com a promulgação da LDB 9394/95, o Desenho Geométrico renasce como ponto de discussão e suas evidências recomeçam nos Parâmetros Curriculares Nacionais de 1998 ao empregarem o uso de "[...] régua e compasso e a utilização de outros instrumentos, como, por exemplo, esquadro e transferidor" (p. 68) nas aulas de matemática. A partir de então, o Desenho Geométrico retoma as salas de aula e sua aplicação é evidenciada no próprio documento ao informar que

O trabalho com espaço e forma pressupõe que o professor de Matemática explore situações em que sejam necessárias algumas construções geométricas com régua e compasso, como visualização e aplicação de propriedades das figuras, além da construção de outras relações (BRASIL, 1998, p. 51).

Dessa forma, é importante apreender que "o desenho geométrico constitui um elemento fundamental para a apropriação dos conceitos geométricos" (QUEIROZ, 2010, p.7). Para Marinho et al (2010), representa um conjunto de técnicas e processos para construções de formas geométricas e não distante, Albrecht e Oliveira (2013, p. 7), afirmam que "o Desenho Geométrico é um conjunto de técnicas utilizadas para construção de formas geométricas desenvolvidas na resolução de problemas para obter-se respostas tão precisas quanto possível". Outras contribuições são apontadas por Albrech e Oliveira (2013): a) o Desenho Geométrico possibilita resolver problemas de natureza prática ou teórica com rapidez e clareza; b) a exatidão e a precisão exigidas no Desenho Geométrico fazem dele um aliado importante na aplicação de conceitos da Geometria e c) permite que os estudantes desenvolvam as habilidades de visualizar, prever e gerar novas ideias.

Segundo Queiroz (2010, p. 8), “o desenho geométrico nos ensina a linguagem gráfica que é uma forma concisa, precisa e universal de comunicar e expressar ideias. Não estudá-lo torna-se uma falha no sistema escolar". Com olhares centrados à Geometria, Marmo e Marmo (1994, p. 12) relatam que "há uma relação perfeita entre o desenho geométrico e a geometria, pois ambas estudam as figuras geométricas com seus conceitos e suas propriedades. O desenho é a geometria gráfica". Dessa forma, Kalter (1996 apud QUEIROZ, 2010) declara que o ensino do Desenho 
Altoé, Romão, Jesus, 2016 - Formação Inicial e Continuada

Geométrico é fundamental para não bloquear as capacidades de planejar, projetar ou abstrair, possibilitando desenvolver a percepção visual e o raciocínio espacial.

Durante as aulas de Geometria é importante apresentar atividades que despertem o pensamento geométrico. Assim, pode-se dizer que o Desenho Geométrico é uma parte da Geometria que, desde a Antiguidade até os dias atuais, contribui na resolução prática de problemas cotidianos (ALBRECHT; OLIVEIRA, 2013), desenvolve a criatividade, o raciocínio, a organização, a iniciativa, a autodisciplina e o capricho (SILVA JUNIOR, 2013).

Portanto, a conexão entre o Desenho Geométrico e Geometria acontece por intermédio das construções geométricas, contribuindo no desenvolvimento do pensamento geométrico e na elaboração de conceitos, otimizando habilidades motoras e cognitivas, estas que conduzem a um melhor aprendizado de Geometria. Sua presença na formação de professores se evidencia quando se coloca em discussão suas implicações na formação do pensamento geométrico, do desenvolvimento de habilidades motoras e visuais, além de oportunizar momentos em sala de aula voltados à exploração, investigação e dedução.

\section{A OFICINA, SUA APLICAÇÃO E RESULTADOS}

Ministrada no VI SEMAT do Ifes, câmpus Cachoeiro de Itapemirim, e intitulada "Desenho Geométrico: Construções Fundamentais", a oficina teve como objetivo discutir sobre o papel do Desenho Geométrico nas aulas de Geometria e sua relevância enquanto temática na Formação Inicial e/ou Continuada de Professores. Direcionou-se à professores do Ensino Fundamental e Médio da Educação Básica e licenciandos em matemática, totalizando 21 (vinte e um) participantes, tendo duração de $2 \mathrm{~h}$. No transcorrer da Oficina, os participantes eram convidados e instigados a refletir e levantar questionamentos a respeito da temática, pois para Freire $(2009, \mathrm{p}$. 24), a reflexão crítica se torna exigência da relação teoria/prática e que "ensinar não é transferir conhecimento, mas criar as possibilidades para a sua produção ou sua construção".

Iniciou-se com uma breve apresentação da história da Geometria e do Desenho Geométrico, destacando suas contribuições na Educação Básica onde, durante as discussões, buscou-se estabelecer relações entre Desenho Geométrico e Geometria. Para tanto, apoiamo-nos nos referenciais apresentados em sessões anteriores. Durante as explanações, os convidados eram incentivados a levantar questionamentos acerca da temática, onde pôde-se perceber pouco 
conhecimento a respeito do Desenho Geométrico. Era visível que conheciam as ferramentas que seriam utilizadas no decorrer das atividades, mas pouco ou nada sabiam de suas funcionalidades ou de como usá-las.

Após essa discussão inicial que durou em torno de $1 \mathrm{~h}$, buscamos propiciar um espaço que pudesse induzir ao pensamento geométrico e, para tanto, propusemos algumas atividades ${ }^{5}$ que abarcavam relacionar o Desenho Geométrico à Geometria. Essas atividades foram realizadas por meio das ferramentas, onde os participantes perceberam que era possível resolvê-las de diferentes maneiras, levando a construção do mesmo conceito geométrico, contudo, por caminhos diferentes. Como forma de sistematização do que foi aprendido, solicitou-se a construção a Figura 1 abaixo.

Figura 1. Igreja construída a partir de elementos geométricos.

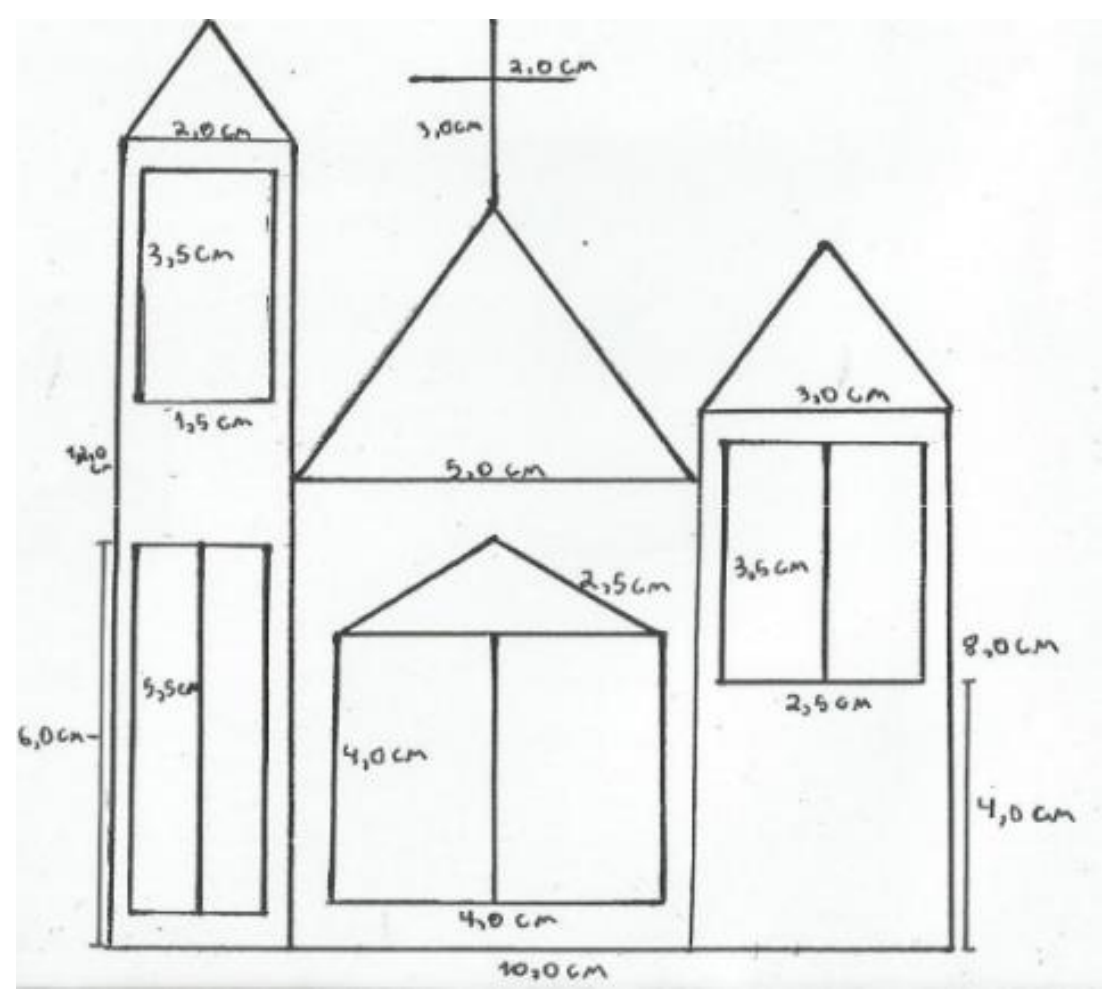

Fonte: Arquivo do pesquisador.

É relevante ressaltar que uma parte significativa dos participantes não demonstravam destreza na utilização das ferramentas. Assim, Albrecht e Oliveira (2013, p. 9) ressaltam que "na prática do

\footnotetext{
${ }^{5}$ Foram propostas atividades como: construção de retas paralelas, perpendiculares, divisão de segmentos em $\mathrm{n}$ partes iguais, determinação de ângulos entre segmentos, construção de bissetriz, divisão de ângulo em $\mathrm{n}$ partes iguais e construção de figuras geométricas.
} 
Desenho Geométrico, ter o material adequado é fundamental, mas não suficiente; é imprescindível saber usá-lo de forma correta". A palavra "material" citada pelos autores alude à palavra "ferramentas" mencionada neste trabalho.

Muitas foram as indagações e dificuldades na hora de manusear as ferramentas, como também, resolver alguns dos problemas: Que caminho seguir? Como o compasso poderá me ajudar? É muito difícil visualizar um possível caminho! Os esquadros facilitam muito a construção de retas paralelas e perpendiculares! Com o uso do compasso, fica fácil transpor medidas! Não sabia que o Teorema de Tales ajudava na divisão de seguimentos e que incrível saber disso! Enfim, essas foram algumas colocações dos participantes, pelas quais percebeu-se muita empolgação com algumas descobertas, outras vezes a falta de visualização geométrica e também, quanto algumas ferramentas ajudavam nas construções e na resolução. Apesar das dificuldades, diferentes resoluções foram apresentadas.

Após a conclusão das atividades, que durou em média 50min, os participantes responderam, voluntariamente, um questionário aberto por meio do qual pudemos levantar possíveis contribuições produzidas pela Oficina. Para preservar a identidade dos mesmos, denominou-se de $\mathrm{P}$ (participantes) numerados de 1 a 21 . Suas falas transcorrer-se-ão fielmente, formatadas em itálico, seguidas de identificação e mês/ano de sua ocorrência. As análises foram organizadas em 3(três) eixos, a citar: i) Eixo 1, que sobre o primeiro objetivo específico; ii) Eixo 2, que trata do segundo objetivo específico e iii) Eixo 3, que debruça-se no terceiro objetivo específico. As respostas a esses eixos serão analisadas à luz dos referenciais teóricos mencionados nas seções anteriores.

Para o Eixo 1, $\mathrm{P}_{4}$ afirma que

a importância da disciplina de Desenho Geométrico na formação dos professores é para agregar fundamentos nos quais exigem várias técnicas do saber e conhecer para transmitir de forma a facilitar o desempenho nas aulas práticas, visão do uso dos objetos associados a teoria abstrata do ensino (Agosto/2014, grifo nosso).

Diante do exposto, inferimos que o participante P4 vê, no Desenho Geométrico, a possibilidade de agregar conhecimentos que podem contribuir nas aulas práticas (construções geométricas nas aulas de Geometria). Além disso, acredita que seu estudo possibilita a visualização de objetos que 
associam-se aos conhecimentos abstratos. De fato, Guarnieri (2011) alega ser o Desenho Geométrico muito importante na representação e visualização de conceitos geométricos. Esses conceitos ausentes de representação gráfica - entendida como Desenho -, mantêm sua abstração e às vezes, incompreensão.

Não muito distante, $P_{3}$ e $P_{11}$ compartilham que a presença do Desenho Geométrico na Formação de Professores contribui nos seus aprendizados uma vez que a relação teoria e prática acontece. Propicia conhecer as ferramentas, suas potencialidades e sua utilização de forma correta. Tais evidências despontam-se na fala de $\mathrm{P}_{18}$ ao anunciar que "o Desenho Geométrico é fundamental para a formação do professor, mostrando como devemos usar os instrumentos e como [se] fazem as formas geométricas" (Agosto/2014). Complementa, de forma similar, $\mathrm{P}_{19}$ ao relatar que por meio dele "[...] nós aprendemos a forma correta de desenhar figuras para podermos desenvolver com nossos alunos no futuro próximo" (Agosto/2014). Nessa perspectiva, "as construções feitas com instrumentos [ferramentas] auxiliam no raciocínio e na execução do conhecimento teórico" (GUARNIERI, 2011, p. 67). Os demais participantes veem, em seu estudo, a oportunidade de aprender melhor a Geometria, de maneira prática e interessante, refletindo em suas ações futuras, sendo então, um componente curricular enriquecedor.

Quando indagados sobre a importância do Desenho Geométrico nas aulas de Geometria, respostas que culminam no Eixo 2, os dados dos questionários foram unanimes: todos ressaltaram a certeza de sua aplicabilidade e relevância na compreensão de conceitos geométricos e estudo da Geometria. Em consonância, $\mathrm{P}_{11}$ menciona que "com a disciplina as aulas ficam dinâmicas $e$ a colaboração em sala de aula talvez fique melhor nas aulas de Geometria" (Agosto/2014). Já com olhares voltados ao desenvolvimento de habilidades, $\mathrm{P}_{12}$ reconhece que o Desenho Geométrico se constitui em

[...] uma maneira diferenciada para aprender conceitos básicos de Geometria, como: ângulos, retas, pontos entre outros axiomas da Geometria Plana, tornando [também] as aulas divertidas. É fundamental para o desenvolvimento da coordenação motora, etc. (Agosto/2014).

Dialogando com P12 e demais ideais anteriormente expostas, Kalter (1986 apud MARINHO et al 2010) sustenta que o ensino de Desenho Geométrico é essencial para que não se bloqueie as 
capacidades de planejar, projetar ou abstrair. Se tratam de habilidades motoras e visuais. Autores como Marmo e Marmo (1994) também veem no Desenho Geométrico a possibilidade de desenvolver hábitos de capricho e habilidades manuais.

Versando nossos olhares ao Eixo 3, todos os participantes responderam que a oficina produziu positivamente reflexões sobre a importância do Desenho Geométrico nas aulas de Geometria. Dessa forma, $\mathrm{P}_{5}$ atesta que

Foi possivel verificar e comprovar a importância de conhecer os instrumentos [ferramentas] próprios para o desenho geométrico. Esta oficina [me] proporcionou o contato com os instrumentos geométricos e melhor compreensão dos conceitos de retas, ângulos, pontos, etc. (Agosto/2014).

Ainda, nessa perspectiva, $\mathrm{P}_{7}$ certifica ao dizer

[...] percebi o quanto é importante trazer essas ferramentas para dentro de sala de aula e trabalhar com os alunos. Vi o quanto a aula fica dinâmica e atrativa. Trabalhamos com indivíduos que não querem ficar apenas sentados e escrevendo o que está no quadro, mas pessoas que precisam de conhecimentos que os envolvam e chamem a sua atenção (Agosto/2014, grifo nosso).

É possível apreender da fala de $\mathrm{P}_{5}$ e $\mathrm{P}_{7}$ suas satisfações em terem participado da oficina. Esta lhes proporcionou conhecer as ferramentas, suas potencialidades na aprendizagem, tornando a aula dinâmica e atrativa. Já para $\mathrm{P}_{12}$, Ihe viabilizou aprender novas formas de realizar as construções geométricas. Não distante, $\mathrm{P}_{13}$ expõe sua satisfação ao narrar que a "[...] oficina ampliou a sua visão sobre a utilização dos instrumentos (Régua, Compasso, Esquadros e Transferidores)" (Agosto/2014).

É comumente sabido que as ferramentas utilizadas possuem demais funcionalidades. Assim, P4 expressa sua opinião dizendo que através da oficina foi possível entender as várias utilidades do compasso e de todos os materiais, enriquecendo a prática nas salas de aula.

Durante o desenvolvimento da Oficina e em conversa com alguns dos participantes, os mesmos relataram não terem ouvido falar ou tiveram ou tem a disciplina de Desenho Geométrico na 
Graduação. Para muitos, a Geometria e o Desenho Geométrico eram um só componente curricular. Não havia distinção.

Para além das contribuições apresentadas até aqui, o participante $P_{15}$ encontrou na Oficina o início de novas descobertas, ao afirmar que "além de tudo o que foi aprendido, os conhecimentos adquiridos [na oficina] despertou-me o prazer em conhecer ainda mais sobre a disciplina de Desenho Geométrico" (Agosto/2014).

Assim, os pronunciamentos apontam que a Oficina possibilitou discutir, refletir e aprender sobre a temática, trazendo contribuições didático-pedagógicas para a prática em sala de aula da Educação Básica.

\section{CONSIDERAÇÕES FINAIS}

Em resposta ao objetivo geral deste trabalho, podemos destacar algumas contribuições produzidas durante a Oficina, tais como: a) possibilitou agregar conhecimentos que podem contribuir nas aulas de Geometria; b) mostrou a importância de conhecer as ferramentas próprias do Desenho Geométrico para melhor ensinar a Geometria; c) proporcionou aprender como se manuseiam as ferramentas, compreendendo sua importância na resolução de atividades; d) percebeu-se que o Desenho Geométrico torna as aulas de Geometria mais dinâmicas e atrativas e e) despertou o prazer em conhecer ainda mais a respeito do Desenho Geométrico. Vemos que a Oficina contribuiu na formação dos licenciandos e professores envolvidos nas discussões, a medida que aproximou aspectos teórico-didáticos do Desenho Geométrico nas aulas de Geometria.

\section{REFERÊNCIAS}

ALTOÉ, R. O.; ROMÃO, G. N. A de O. Desenho Geométrico: construções fundamentais. VI Seminário da Licenciatura em Matemática (VI SEMAT). 2014.

ALBRECHT, C. F.; OLIVEIRA, L. B. de. Desenho Geométrico. Viçosa: Ed. UFV, 2013.

BRASIL. Parâmetros curriculares nacionais - terceiro e quarto ciclos do ensino fundamental: matemática. Brasília, DF: MEC/SEF, 1998.

BOYER, C. B. História da Matemática. 3. ed. São Paulo: Blucher, 2010.

BONGIOVANNI, V.; SAVIETTO, E.; MOREIRA, L.; Desenho Geométrico para o 2o Grau. São Paulo, Editora Ática, 2007.

EVES, H. Introdução à história da matemática. Campinas, SP: Editora da Unicamp, 2004. 
FONSECA, M. da C. F. R. et al. O ensino de geometria na escola fundamental: três questões para a formação do professor dos ciclos. Belo Horizonte: Autêntica, 2011. 128 p.

FREIRE, P. Pedagogia da Autonomia: saberes necessários à prática educativa. 51.ed. Rio de Janeiro: Paz e Terra, 2015.

GUARNIERI, D. A importância do Desenho Geométrico para melhor qualidade do Ensino de Geometria. Diálogos \& Saberes, Mandaguari, v. 7, n. 1, p. 67-71, 2011.

HOFFER, A. Geometry is more than Proof. The Mathematics Teachers, vol. 74, n. 1, USA, Janeiro 1981.

KALEFF, A. M. M. R. et al. Quebra-cabeça geométricos e formas planas. 3. ed. Niterói: EdUFF, 2005.87 p.

LORENZATO, S. L. Por que não ensinar geometria? A Educação Matemática em Revista, SBEM, no 4, 1 semestre, 1995.

LISBOA, E. Q. O Desenho Geométrico como disciplina de curso de licenciatura em matemática: uma perspectiva histórica. Dissertação de Mestrado Profissional em Educação Matemática. Juíz de Fora - MG, 2013.

MARMO, C.; MARMO, N.; Desenho Geométrico. Vol 1, Editora Scipione, São Paulo 1994.

MARINHO, J. et al. A importância do Desenho Geométrico no ensino básico e técnico de nível médio. 1ạ Jornada de Iniciação Científica e Extensão do IFTO. 2010.

MOL, R. S. Introdução a história da matemática. Belo Horizonte: CAED-UFMG, 2013. 138 p.

PAVANELLO, M. R. O abandono do ensino da geometria no Brasil: causas e consequências. In: Revista Zetetiké, ano 1, no 1, p. 07-17. São Paulo: UNICAMP, Faculdade de Educação, 1993.

QUEIROZ, J. C. S. A geometria e o desenho geométrico nas escolas do Brasil no século XX. X Encontro Nacional de Educação Matemática. Salvador/BA. 2010.

SANTOS, C. A. dos; NACARATO, A. M. Aprendizagem em Geometria na educação básica: a fotografia e a escrita na sala de aula. 1. ed. Belo Horizonte: Autêntica Editora, 2014.

ZUIN, E. de S. L. Construções geométricas, um saber escolar novamente para todos? In: Semana da Pós-graduação da UFMG, Belo Horizonte. Anais, Universidade Federal de Minas Gerais, 2002.

. A valorização do ensino do desenho geométrico nas escolas de Minas Gerais nas primeiras décadas do século XX (1906-1927). Anais do II Congresso de Pesquisa e Ensino em História da Educação em Minas Gerais. Uberlândia - MG, 2003. 